\title{
Erratum to: Description of Hymenobacter arizonensis sp. nov. from the southwestern arid lands of the United States of America
}

\author{
Gundlapally S. N. Reddy • Ferran Garcia-Pichel
}

Published online: 1 November 2012

(C) Springer Science+Business Media Dordrecht 2012

\section{Erratum to: Antonie van Leeuwenhoek DOI 10.1007/s10482-012-9812-1}

In the original published article, the accession number of the strain $H$. rigui in Fig. 3 is incorrect.
The correct accession number of the strain $H$. rigui in Fig. 3 is DQ089669.

The online version of the original article can be found under doi:10.1007/s10482-012-9812-1.

G. S. N. Reddy $(\bowtie) \cdot$ F. Garcia-Pichel

School of Life Sciences, Arizona State University, Main

Campus, Tempe, AZ 85287-4501, USA

e-mail: rukmagsn@gmail.com

Present Address:

G. S. N. Reddy

Centre for Cellular and Molecular Biology, Uppal Road,

Hyderabad 500007, India 


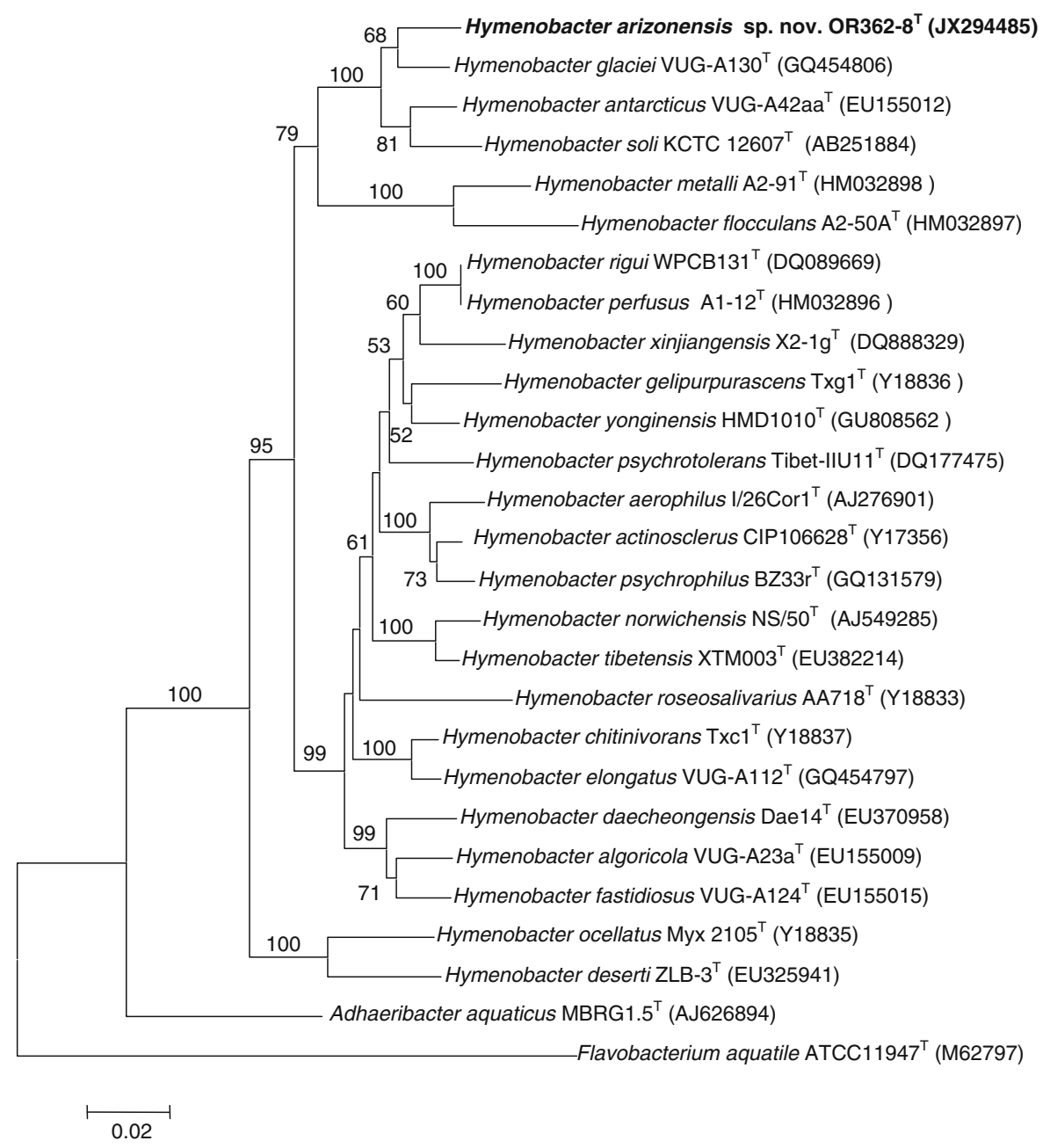

Fig. 3 A neighbour-joining tree based on 16S rRNA gene sequences showing the phylogenetic relationship between $H$. arizonensis sp. nov. $\left(\mathrm{OR} 362-8^{\mathrm{T}}\right)$ and other closely related species. Bootstrap values (expressed as percentages of 1000 replications) greater than $40 \%$ are indicated at the nodes. Flavobacterium aquatile ATCC $11947^{\mathrm{T}}$ was used as an outgroup 